\title{
BMJ open Large-scale international validation of the ADO index in subjects with COPD: an individual subject data analysis of 10 cohorts
}

\author{
Milo A Puhan, ${ }^{1,2}$ Nadia N Hansel, ${ }^{3}$ Patricia Sobradillo, ${ }^{4}$ Paul Enright, ${ }^{5}$ \\ Peter Lange, ${ }^{6}$ DeMarc Hickson, ${ }^{7,8}$ Ana M Menezes, ${ }^{9}$ Gerben ter Riet, ${ }^{10}$ \\ Ulrike Held, ${ }^{2}$ Antonia Domingo-Salvany, ${ }^{11,15}$ Zab Mosenifar, ${ }^{12}$ \\ Josep M Antó, ${ }^{11,13,14,15}$ Karel G M Moons, ${ }^{16}$ Alphons Kessels, ${ }^{17}$ \\ Judith Garcia-Aymerich, ${ }^{11,13,14,15}$ for the International COPD \\ Cohorts Collaboration Working Group
}

To cite: Puhan MA, Hansel NN, Sobradillo P, et al. Large-scale international validation of the ADO index in subjects with COPD: an individual subject data analysis of 10 cohorts. BMJ Open 2012;2:e002152. doi:10.1136/bmjopen-2012002152

- Prepublication history and additional material for this paper are available online. To view these files please visit the journal online (http://dx.doi.org/10.1136/ bmjopen-2012-002152).

Received 22 September 2012 Revised 6 November 2012 Accepted 12 November 2012

This final article is available for use under the terms of the Creative Commons Attribution Non-Commercial 2.0 Licence; see http://bmjopen.bmj.com

MAP and JGA contributed equally to this study.

For numbered affiliations see end of article.

\section{Correspondence to} Dr Judith Garcia-Aymerich; jgarcia@creal.cat

\section{ABSTRACT}

Background: Little evidence on the validity of simple and widely applicable tools to predict mortality in patients with chronic obstructive pulmonary disease (COPD) exists.

Objective: To conduct a large international study to validate the ADO index that uses age, dyspnoea and $\mathrm{FEV}_{1}$ to predict 3-year mortality and to update it in order to make prediction of mortality in COPD patients as generalisable as possible.

Design: Individual subject data analysis of 10 European and American cohorts ( $n=13$ 914).

Setting: Population-based, primary, secondary and tertiary care.

Patients: COPD GOLD stages I-IV.

Measurements: We validated the original ADO index. We then obtained an updated ADO index in half of our cohorts to improve its predictive accuracy, which in turn was validated comprehensively in the remaining cohorts using discrimination, calibration and decision curve analysis and a number of sensitivity analyses.

Results: 1350 (9.7\%) of all subjects with COPD (60\% male, mean age 61 years, mean $\mathrm{FEV}_{1} 66 \%$ predicted) had died at 3 years. The original ADO index showed high discrimination but poor calibration $(p<0.001$ for difference between predicted and observed risk). The updated ADO index (scores from 0 to 14) preserved excellent discrimination (area under curve 0.81, 95\% $\mathrm{Cl} 0.80$ to 0.82 ) but showed much improved calibration with predicted 3-year risks from $0.7 \%$ (95\% $\mathrm{Cl} 0.6 \%$ to $0.9 \%$, score of 0 ) to $64.5 \%(61.2 \%$ to $67.7 \%$, score of 14$)$. The ADO index showed higher net benefit in subjects at low-to-moderate risk of 3-year mortality than $\mathrm{FEV}_{1}$ alone.

Interpretation: The updated 15-point ADO index accurately predicts 3-year mortality across the COPD severity spectrum and can be used to inform patients about their prognosis, clinical trial study design or benefit harm assessment of medical interventions.

\section{ARTICLE SUMMARY}

Article focus

- We aimed to conduct a large international study to validate the ADO index that uses age, dyspnoea and $\mathrm{FEV}_{1}$ to predict 3-year mortality and to update it in order to make prediction of mortality in chronic obstructive pulmonary disease (COPD) patients as generalisable as possible.

\section{Key messages}

- The updated 15-point AD0 index accurately predicts 3-year mortality across the COPD severity spectrum (GOLD stage I-IV), settings (general population, primary care and specialised care) and geographical area.

- The updated ADO index can be used to inform patients, clinical trial study design and benefit harm assessment of medical interventions on a population level or individual level.

- In addition, the ADO index could serve as a reference standard for risk prediction against which the additional value of various biomarkers to predict mortality could be assessed.

Strengths and limitations of this study

- The study includes a large sample size from 10 European and American cohorts and covers the entire COPD severity spectrum, which increases external validity.

- The study uses information readily available in routine clinical practices.

- Focus on mortality and easily available predictors.

\section{INTRODUCTION}

Chronic obstructive pulmonary disease (COPD) is among the leading causes of death worldwide. ${ }^{12}$ Although the substantial excess mortality associated with COPD is well 
recognised from a public health standpoint, relatively little evidence is available on how to estimate the risk of mortality for an individual patient. Tools to accurately project the clinical course of the disease, including prediction of outcomes such as mortality, exacerbations or quality of life, would inform patients and their caregivers about prognosis and allow for a better understanding of the benefits and harms of possible treatments. ${ }^{3-6}$ Also, tools that incorporate prognostic information from easily available parameters could serve as reference against which the additional prognostic value of biomarkers could be assessed.

Current international COPD guidelines provide little guidance on how to assess a patient's prognosis. ${ }^{7}$ This is likely due, in large part, to the scarcity of evidence on how to accurately estimate prognosis in patients with COPD; however, this is in contrast to other chronic disease guidelines that have clear recommendations on the use of prognostic indices to inform patients and to guide treatment decisions. ${ }^{9-13}$ Prognostic indices for COPD have recently received increased attention, but have seen little application in clinical practice. This may be because indices, to date, have either required information not readily available in routine clinical practice, ${ }^{14}$ do not provide explicit outcome risks ${ }^{15}{ }^{16}$ or have received minimal validation. ${ }^{15-17} \mathrm{~A}$ recently developed index, the $\mathrm{ADO}$ index, combines age, dyspnoea and airflow obstruction to predict the risk of mortality. It may have great potential for widespread application because of its simplicity. However, formal testing of its accuracy across a variety of COPD patient cohorts following standard methods has not yet been done. ${ }^{6}{ }^{18-21}$ The original index was derived in a cohort of moderateto-severe COPD patients from specialised care, therefore, it requires validation in larger and notably more diverse COPD populations. We conducted such large-scale international validation of the ADO index to determine how well it predicts mortality for individual subjects with COPD from diverse settings, and updated the index as needed.

\section{METHODS}

Cohorts and patients

Investigators from $10 \mathrm{COPD}$ and population-based cohort studies in Europe and the Americas agreed to collaborate in the International COPD Cohorts Collaboration Working Group. These cohorts include the Barmelweid cohort (Switzerland, clinic based), ${ }^{17}$ the Basque study (Spain, clinic based), ${ }^{22}$ the Cardiovascular Health Study (CHS, USA, population based), ${ }^{23}$ the Copenhagen City Heart Study (CCHS, Denmark, population based), ${ }^{24}$ the Jackson Heart Study (JHS, USA, population based), ${ }^{25}$ the Lung Health Study (LHS, USA, clinic based) ${ }^{26}$ the cohort from which patients for the National Emphysema Treatment Trial were recruited (NETT, USA, clinic based), ${ }^{27}$ the Phenotype and Course of COPD PAC-COPD Study (PAC-COPD, Spain, clinic based), ${ }^{28}$ the PLATINO study (Uruguay, population based), ${ }^{29}$ and the Quality of Life of COPD Study Group (SEPOC, Spain, clinic based). ${ }^{30}$ Details about the cohorts are provided in the online supplement (see online supplementary appendix 1). From this international pool of cohorts we selected participants with at least 40 years of age and with COPD defined by spirometry as a post-bronchodilator (BD) $\mathrm{FEV}_{1} / \mathrm{FVC} \leq 0.7$, except for the CHS and CCHS cohorts where post-BD was not available and pre-BD values were used. Thus, our large pool of cohorts represents a heterogeneous group of subjects, combining (1) COPD patients from clinical cohorts and (2) subjects with evidence of airway limitation from the population-based cohorts, but without a confirmed diagnosis of COPD. Ethics Board approval was obtained in all cohorts.

\section{Mortality and candidate predictors of mortality}

All-cause mortality at 3 years was defined as the outcome. It was obtained from personal follow-up of patients or relatives, national registries, or hospital records, yielding no missing information with respect to mortality. We considered potential predictors of mortality which are easy to obtain across diverse medical settings. These variables included age, sex, smoking status, prebronchodilator or postbronchodilator $\mathrm{FEV}_{1}$ as available, dyspnoea score (Medical Research Council Dyspnea scale), respiratory signs and symptoms (cough, sputum and wheezing), body mass index (BMI), asthma and cardiovascular disease (CVD, which included ischaemic heart disease, stroke, congestive heart failure or peripheral vascular disease). As in previous analyses, ${ }^{17}$ we explicitly excluded potential predictors of mortality which are more burdensome to measure such as exercise capacity (eg, $6 \mathrm{~min}$ walked distance) or arterial blood gases, since these are unlikely to be available consistently in clinical practice outside academic centres. Missing values were imputed using 10-fold multiple imputation for each cohort, using the remaining variables as predictors. ${ }^{31} 32$ Methods used for collecting and harmonising data, and for handling missing data are detailed in the appendix (see online supplementary appendices 2-4).

\section{Statistical analysis}

A detailed version of statistical analysis including sample size assessment is available in the appendix (see online supplementary appendix 5 ).

We first validated the original ADO index ${ }^{17}$ through the assessment of its discrimination (area under curve) and calibration (comparison of predicted vs observed risk) properties in all subjects except for those included in the original derivation cohort (ie, the Barmelweid study).

In order to make the risk estimation tool as generalisable to different international populations as possible, we then updated the ADO index following standardised procedures that first included an updating or adjustment 
of the intercept only followed by, if necessary, more extensive updates including model revision (refitting the predictor-outcome associations) and model extension (adding new predictors). ${ }^{21} 32$ Model refitting of the ADO index was performed using all subjects from the CCHS, LHS, NETT, PLATINO and PAC-COPD cohorts (update cohort, $\mathrm{n}=10$ 221), applying logistic regression with death as the outcome variable and age, dyspnoea and $\mathrm{FEV}_{1}$ as predictors. Then the validation (discrimination and calibration) of the final updated ADO index was done with the subjects from the Barmelweid study, CHS, Basque Study, JHS and SEPOC cohorts (validation cohort, $n=3693$ ). Thus, both update and validation sets included a large number of subjects with COPD or airflow limitation, diverse in terms of disease severity (GOLD I-IV) and settings (general population, primary care and specialised care). We translated the final model into a simple-to-use 15 -point scale. ${ }^{33}$

To further quantify the accuracy of the updated ADO index, we performed a decision curve analysis that compares the net benefit of different approaches. Net benefit is defined as the difference between the proportion of subjects that are correctly identified to be at or above a certain risk threshold (eg, 5\% risk) and the proportion of subjects incorrectly identified to be at or above that threshold. We focused on subjects with COPD at low-to-moderate risk for 3-year mortality $(<20 \%)$ where most uncertainty about the balance between benefits and harms of treatments may exist so that risk thresholds may be specifically useful. ${ }^{34} 35$

Finally, we explored whether adding new predictors (eg, CVD, BMI and sex) improved the updated (refitted) models' discrimination and calibration and we conducted three sensitivity analyses that tested how susceptible our results were to analytical approaches taken. All analyses were repeated: (1) using multilevel (rather than conventional) logistic regression analysis; (2) excluding subjects with mild COPD (GOLD stage I) and (3) excluding subjects with a physician diagnosis of asthma from cohorts where only prebronchodilator spirometry was available. We also considered restricting the analyses to subjects with an $\mathrm{FEV}_{1} / \mathrm{FVC}$ ratio below their lower limit of normal level according to local prediction equations, but the number of subjects not fulfilling this criterion was very low $(<1 \%)$.

We conducted all analyses using Stata for Windows (V.11.1, College Station, Texas, USA) and R, V.2.12 ( $\mathrm{R}$ Foundation for Statistical Computing, Vienna, Austria, 2011).

\section{RESULTS}

In total, 13914 subjects with COPD (60\% men) were included in the analysis (table 1 ). On average, subjects were approximately 61 years old, with moderate airflow limitation and mild dyspnoea; however, there was a wide range of disease severity within and across cohorts. The majority of subjects were former or current smokers
$(89 \%)$ and $22 \%$ had concomitant CVD. After 3 years $1350(9.7 \%)$ subjects had died.

The original ADO index showed high discrimination (see online supplementary appendix 6) but poor calibration with a substantial mismatch between predicted and observed risks across the entire risk spectrum. Updating the intercept only did not substantially improve this miscalibration. Therefore, we decided to update the original ADO index.

In the update cohort, the updated ADO model showed very good agreement between predicted and observed 3-year mortality risk across 10 equally sized groups of subjects with increasing predicted risk (figure 1: mean predicted risk $9.1 \%$ ). More importantly, in the validation cohort, the updated index still had good prediction across all risk categories, in particular in subjects at mortality risks below $20 \%$. There was only a slight overprediction among subjects at very high risk. This validation did not indicate a need for further adjustment of the intercept or regression coefficients of the updated ADO model, which indicated good generalisability across countries and settings. Discrimination was, as expected, somewhat lower in the validation cohort but still 0.73 (95\% CI $0.70 \%$ to $0.76 \%)$. Further extensions of the updated ADO index by adding CVD, BMI and sex did not substantially improve the model's discrimination or calibration, even though all three predictors were significantly associated with mortality in the multivariate model (all $\mathrm{p}$ values $<0.05)$. The area under the curve remained 0.85 in the update cohort and 0.74 in the validation cohort, and the calibration also remained good (see online supplementary appendix 7).

Tables 2 and 3 show the updated ADO index where the strength of association of age, dyspnoea and $\mathrm{FEV}_{1}$ with 3 -year mortality is reflected in the regression coefficients and the corresponding integer point score. The 3-year risks of mortality associated with ADO scores are shown in table 4 and range from $0.7 \%$ (95\% CI $0.6 \%$ to $0.9 \%$ ) with a score of zero to $64.5 \%(95 \%$ CI $61.2 \%$ to $67.7 \%)$ at a point score of 14 . The area under the curve of the updated ADO index is 0.81 (95\% CI $0.80 \%$ to $0.82 \%)$.

Figure $2 \mathrm{~A}$ shows that, from $1 \%$ to $20 \%$ risk of 3 -year mortality, using the updated ADO index (regression equation) is consistently more accurate to classify patients correctly above or below certain risk thresholds than using either of the three predictors alone. Figure 2B shows the consequences of more accurate risk classification. For example at a risk threshold of $5 \%$, using the ADO index would result in a reduction of the number of patients classified incorrectly to be above $5 \%$ by 33/100 subjects compared with considering all patients to be above $5 \%$ (ie, without using any predictors), and compared with using only $\mathrm{FEV}_{1}$ (18 per 100 subjects), age (24 per 100 subjects) or dyspnoea (10 per 100 subjects). At higher risk thresholds, the updated $\mathrm{ADO}$ index and $\mathrm{FEV}_{1}$ perform similarly.

Discrimination, calibration and the analysis of accuracy for risk thresholds remained essentially 
Table 1 Description of sociodemographic and clinical characteristics of 13914 subjects with COPD from the cohorts

\begin{tabular}{|c|c|c|c|c|c|c|c|c|c|c|c|}
\hline & & $\begin{array}{l}\text { Barmelweid } \\
\text { cohort }\end{array}$ & $\begin{array}{l}\text { Basque } \\
\text { study }\end{array}$ & $\begin{array}{l}\text { Cardio-vascular } \\
\text { Health Study }\end{array}$ & $\begin{array}{l}\text { Copenhagen } \\
\text { City Heart } \\
\text { Study }\end{array}$ & $\begin{array}{l}\text { Jackson } \\
\text { Heart } \\
\text { Study }\end{array}$ & $\begin{array}{l}\text { Lung } \\
\text { Health } \\
\text { Study }\end{array}$ & $\begin{array}{l}\text { National } \\
\text { Emphysema } \\
\text { Treatment } \\
\text { Trial }\end{array}$ & $\begin{array}{l}\text { PAC-COPD } \\
\text { Study }\end{array}$ & $\begin{array}{l}\text { PLATINO } \\
\text { study }\end{array}$ & $\begin{array}{l}\text { SEPOC } \\
\text { study }\end{array}$ \\
\hline & $\begin{array}{l}\text { Total } \\
n=13914\end{array}$ & $\begin{array}{l}\text { Switzerland, } \\
\text { Europe } \\
n=231\end{array}$ & $\begin{array}{l}\text { Spain, } \\
\text { Europe } \\
n=106\end{array}$ & $\begin{array}{l}\text { USA, North } \\
\text { America } \\
\mathrm{n}=2619\end{array}$ & $\begin{array}{l}\text { Denmark, } \\
\text { Europe } \\
\mathrm{n}=2287\end{array}$ & $\begin{array}{l}\text { USA, North } \\
\text { America } \\
n=419\end{array}$ & $\begin{array}{l}\text { USA, North } \\
\text { America } \\
n=5167\end{array}$ & $\begin{array}{l}\text { USA, North } \\
\text { America } \\
\mathrm{n}=\mathbf{2 2 5 2}\end{array}$ & $\begin{array}{l}\text { Spain, } \\
\text { Europe } \\
\mathrm{n}=342\end{array}$ & $\begin{array}{l}\text { Uruguay, } \\
\text { South } \\
\text { America } \\
n=173\end{array}$ & $\begin{array}{l}\text { Spain, } \\
\text { Europe } \\
n=318\end{array}$ \\
\hline $\begin{array}{l}\text { Age (years), } \\
\text { mean (SD) }\end{array}$ & $60.8(11.6)$ & $72.4(8.8)$ & $70.5(8.9)$ & $73.6(5.9)$ & $60.7(9.4)$ & $62.4(11.0)$ & $50.1(5.7)$ & $66.7(6.3)$ & $67.9(8.6)$ & $67.2(11.3)$ & $65.2(9.2)$ \\
\hline $\begin{array}{l}\text { Sex: male, } n \\
(\%)\end{array}$ & $8324(60)$ & $138(60)$ & $104(98)$ & $1341(51)$ & $1235(54)$ & $184(44)$ & 3223 (62) & $1366(61)$ & $318(93)$ & $97(56)$ & $318(100)$ \\
\hline $\begin{array}{l}\text { Working status: } \\
\text { active, } \mathrm{n}(\%)\end{array}$ & $5297(63)$ & n.a. & n.a. & n.a. & n.a. & $413(99)$ & 4538 (88) & $178(8)$ & $61(18)$ & $63(36)$ & $51(16)$ \\
\hline \multicolumn{12}{|l|}{ Smoking } \\
\hline Never, n (\%) & $1452(11)$ & $9(5)$ & $0(0)$ & $930(36)$ & $215(9)$ & $215(52)$ & $0(0)$ & $12(1)$ & $2(1)$ & $57(33)$ & $12(5)$ \\
\hline $\begin{array}{l}\text { Former, } \\
\mathrm{n}(\%)\end{array}$ & 4751 (34) & $138(73)$ & $82(77)$ & $1245(48)$ & 443 (19) & $102(25)$ & $73(1)$ & $2240(100)$ & $220(67)$ & $60(35)$ & $148(58)$ \\
\hline $\begin{array}{l}\text { Current, } \\
\mathrm{n}(\%)\end{array}$ & $7590(55)$ & $41(22)$ & $24(23)$ & $444(17)$ & $1626(71)$ & $99(24)$ & 5094 (99) & $0(0)$ & 109 (33) & $56(32)$ & $97(38)$ \\
\hline $\begin{array}{l}\text { Body mass } \\
\text { index }\left(\mathrm{kg} / \mathrm{m}^{2}\right) \text {, } \\
\text { mean }(\mathrm{SD})\end{array}$ & $25.7(4.5)$ & $25.9(6.1)$ & $26.1(4.9)$ & $26.2(4.8)$ & $25.0(4.2)$ & $29.6(7.5)$ & $25.6(3.9)$ & $24.9(4.2)$ & $28.2(4.7)$ & $27.4(5.3)$ & 26.4 (4.2) \\
\hline $\begin{array}{l}\text { Dyspnoea } \\
\text { (MRC, 0-4), } \\
\text { mean (SD) }\end{array}$ & $1.1(1.3)$ & $2.2(1.2)$ & $2.0(0.6)$ & $0.8(1.1)$ & $1.1(1.3)$ & $0.2(0.6)$ & $0.6(0.8)$ & $2.7(1.0)$ & $2.2(1.0)$ & $0.6(0.6)$ & $2.1(1.5)$ \\
\hline Cough, n (\%) & 4009 (59) & n.a. & n.a. & 444 (17) & n.a. & $108(26)$ & 3259 (100) & n.a. & $138(41)$ & $60(35)$ & n.a. \\
\hline Sputum, n (\%) & 4289 (52) & n.a. & n.a. & $656(25)$ & $908(40)$ & $107(26)$ & $2400(100)$ & n.a. & $172(51)$ & $46(27)$ & n.a. \\
\hline Wheeze, n (\%) & $4352(53)$ & n.a. & n.a. & $187(9)$ & n.a. & $73(18)$ & $3897(75)$ & n.a. & $125(37)$ & $70(40)$ & n.a. \\
\hline $\begin{array}{l}\mathrm{FEV}_{1}(\% \text { pred }) \\
\text { mean }(\mathrm{SD})^{*}\end{array}$ & $65.9(24.8)$ & $45.1(16.1)$ & $46.9(11.4)$ & $77.3(22.4)$ & $70.5(23.7)$ & $71.2(20.5)$ & $77.8(9.1)$ & $27.5(8.9)$ & $52.4(16.2)$ & $84.3(18.1)$ & $45.0(18.3)$ \\
\hline $\begin{array}{l}\text { Inhaler steroid } \\
\text { use, } \mathrm{n}(\%)\end{array}$ & $1833(33)$ & - & $103(100)$ & $55(2)$ & n.a. & n.a. & n.a. & $1376(61)$ & $266(79)$ & $33(19)$ & n.a. \\
\hline $\begin{array}{l}\text { 6-min walk } \\
\text { distance, } \\
\text { mean (SD) }\end{array}$ & $\begin{array}{l}357.8 \\
(111.7)\end{array}$ & $363.1(127.0)$ & $\begin{array}{l}442.9 \\
(95.4)\end{array}$ & n.a. & n.a. & n.a. & n.a. & $340.6(106.3)$ & $435.5(90.6)$ & n.a. & n.a. \\
\hline Asthma, $\uparrow \mathrm{n}(\%)$ & $920(8)$ & $0(0)$ & $0(0)$ & $148(6)$ & $246(11)$ & $74(18)$ & $373(7)$ & n.a. & $30(9)$ & $49(28)$ & $0(0)$ \\
\hline $\begin{array}{l}\text { Diabetes, } \dagger \\
\mathrm{n}(\%)\end{array}$ & $262(7)$ & $41(18)$ & n.a. & n.a. & $60(3)$ & $71(19)$ & n.a. & n.a. & 65 (19) & $7(4)$ & $18(6)$ \\
\hline
\end{tabular}




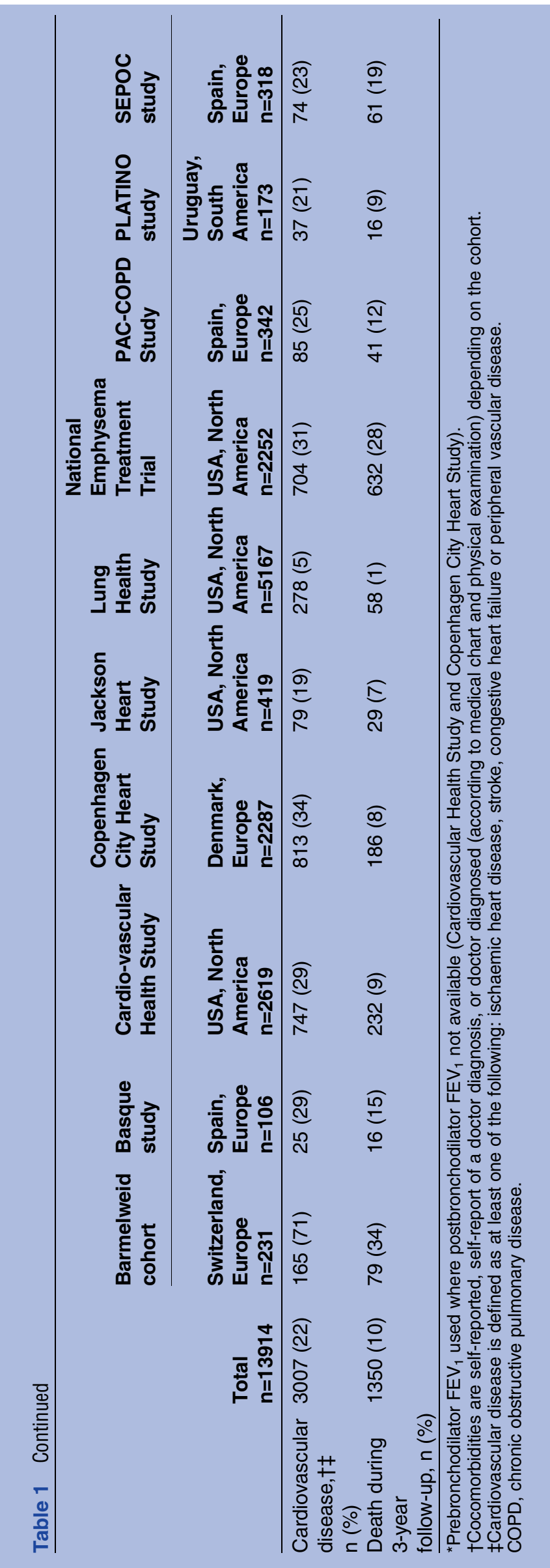

unchanged in all sensitivity analyses (see online supplementary appendix 8 ).

\section{DISCUSSION}

Our study showed that the updated ADO index, ranging from 0 to 14 , accurately predicts 3-year mortality in subjects with COPD. We found that adding CVD, BMI or sex does not significantly improve prediction of mortality when added to age, dyspnoea and $\mathrm{FEV}_{1}$. Importantly, these results were consistent in sensitivity analyses and across very diverse COPD populations. Based on these results, the updated $\mathrm{ADO}$ index has the potential to provide COPD patients with accurate prognostic information on mortality.

The interest in prognostic assessment of COPD has resulted in several prognostic tools. ${ }^{15-17}$ The latter had, however, little impact on clinical guidelines or practice so far. The current study overcomes potentially important barriers to the use of previously published prognostic tools by providing an extensive, international validation of a simple tool. The first step of our analysis, the large-scale validation of the original ADO index, showed that mortality could not be predicted accurately but that the combination of age, dyspnoea and $\mathrm{FEV}_{1}$ is highly discriminative. Therefore, a more extensive update than just an adjustment for different underlying risks was necessary and we updated the entire regression model in our very diverse update cohort that represented the entire disease spectrum. The resulting updated ADO index showed excellent calibration and discrimination in both the update and validation cohorts. An additional adjustment was not deemed necessary for the validation cohort, which may be due to the great diversity of the update and validation cohorts in terms of disease severity, clinical setting and geographical area. Our results confirm that CVD and low BMI are important comorbidities in COPD patients and are significantly associated with mortality; however, they did not provide additional accuracy in risk prediction when added to age, dyspnoea and $\mathrm{FEV}_{1}$, as shown by the fact that the performance of the ADO index was not improved by adding CVD, sex and BMI to the statistical model.

Informing patients about their prognosis is a core task of clinicians. Patients with chronic disease are particularly interested in the potential course of their disease in order to better understand what a diagnosis such as COPD implies for them. Important outcomes that characterise prognosis are exacerbations, quality of life and mortality. ${ }^{36}$ With the ADO index, we now provide a simple tool that clinicians from any setting can use to estimate the risk of mortality. We propose that such multivariable tools can also be used to balance the benefits and harms of possible treatments since the benefit harm balance depends heavily on the patients' prognosis. ${ }^{4} 37$ Thus, estimation of prognosis is of key importance for patients but also for policy makers, regulatory agencies and clinical guideline developers. Our data suggest that 
Figure 1 Update and validation of the ADO index in 13914 subjects with chronic obstructive pulmonary disease (COPD). The upper part of the figure shows the predictive performance of the updated ADO index in 10221 subjects with COPD from the Copenhagen City Heart Study, Lung Health Study, National Emphysema Treatment Trial, PLATINO and the Phenotype and Course of COPD Study. The calibration plot shows the predicted and observed risks for 10 equally sized group with increasing risk of 3-year mortality. The discrimination plot shows the area under the curve. The lower part of the figure shows the predictive performance of the updated ADO index in the validation cohort with 3693 subjects from the Cardiovascular Health Study, Basque COPD study, Jackson Heart Study, Barmelweid Study and the Quality of Life of Chronic Obstructive Pulmonary Disease Study (SEPOC).
Calibration
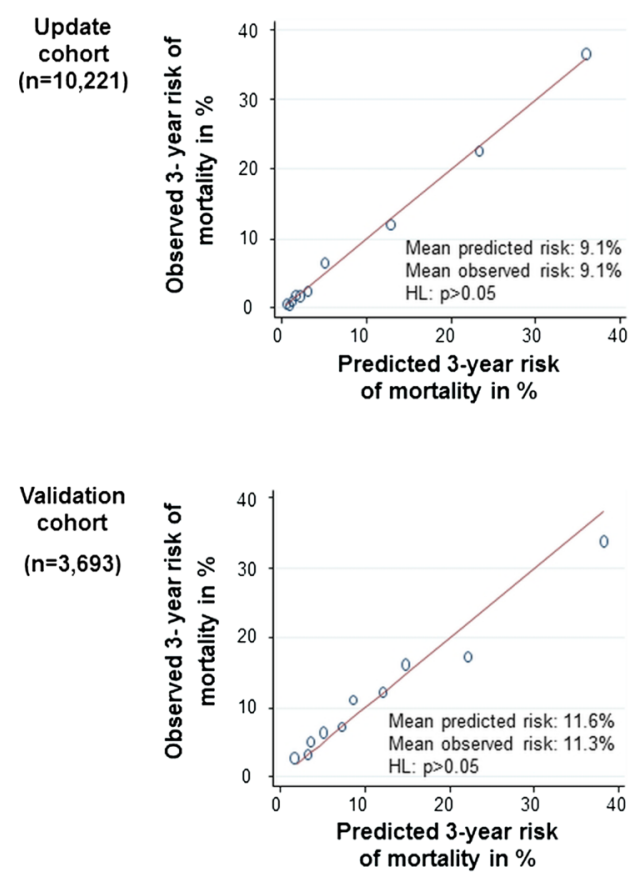

Discrimination
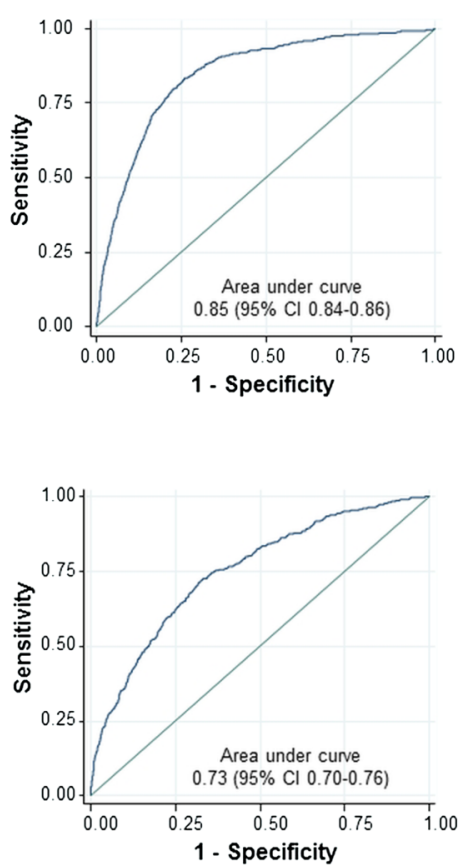

Table 2 Regression coefficients and development of updated ADO index

\begin{tabular}{|c|c|c|c|c|c|}
\hline Variable & $\begin{array}{l}\text { Regression coefficients } \\
\beta_{s} \text { per unit increase }\end{array}$ & Categories & $\begin{array}{l}\text { Reference values } \\
\mathbf{W}_{\mathrm{ij}} \text { (mid point) }\end{array}$ & $\begin{array}{l}\beta_{\mathrm{s}}^{*} \\
\left(W_{\mathrm{ij}}{ }^{*} W_{1 \text { reference }}\right)\end{array}$ & $\begin{array}{l}\text { Risk score }=\beta_{\mathrm{s}}{ }^{\star} \\
\left(\mathrm{W}_{\mathrm{ij}}{ }^{\star} \mathrm{W}_{1 \text { reference }}\right) / \mathrm{B} \dagger\end{array}$ \\
\hline \multirow[t]{5}{*}{$\begin{array}{l}\text { FEV }_{1} \\
\text { (\% predicted) }\end{array}$} & $\begin{array}{l}-0.0288 \\
(S E 0.0023, p<0.0001)\end{array}$ & $\geq 81$ & $87.0\left(\mathrm{~W}_{2 \text { reference }}\right)$ & & 0 \\
\hline & & $\geq 65-80$ & 72.5 & 0.418 & 1 \\
\hline & & $\geq 50-64$ & 57.0 & 0.864 & 2 \\
\hline & & $\geq 36-49$ & 42.5 & 1.282 & 3 \\
\hline & & $\leq 35$ & 25.0 & 1.786 & 4 \\
\hline \multirow[t]{5}{*}{$\begin{array}{l}\text { Dyspnoea } \\
\text { (mMRC, 0-4) }\end{array}$} & $\begin{array}{l}0.2585 \\
(S E 0.0406, p<0.0001)\end{array}$ & $\overline{0}$ & $0\left(\mathrm{~W}_{3 \text { reference }}\right)$ & & 0 \\
\hline & & 1 & 1 & 0.259 & 1 \\
\hline & & 2 & 2 & 0.517 & 1 \\
\hline & & 3 & 3 & 0.776 & 2 \\
\hline & & 4 & 4 & 1.034 & 3 \\
\hline \multirow[t]{5}{*}{ Age (years) } & $\begin{array}{l}0.0703 \\
\text { (SE } 0.0048, p<0.0001)\end{array}$ & $40-49$ & $44.5\left(\mathrm{~W}_{4 \text { reference }}\right)$ & & 0 \\
\hline & & $50-59$ & 54.5 & 0.703 & 2 \\
\hline & & $60-69$ & 64.5 & 1.406 & 4 \\
\hline & & $70-79$ & 74.5 & 2.109 & 5 \\
\hline & & $\geq 80$ & 84.5 & 2.812 & 7 \\
\hline
\end{tabular}

$\dagger 1$ Point is assigned per $15 \%$ in $\mathrm{FEV}_{1}=$ coefficient of 0.40 . Points rounded to the next integer. Constant of regression equation=-5.640. MRC, Medical Research Council. 
Table 3 Assignment of points for the updated ADO index, compared with the original ADO index

\begin{tabular}{|c|c|c|c|c|c|c|c|}
\hline Assignment of points & 0 & 1 & 2 & 3 & 4 & 5 & 7 \\
\hline \multicolumn{8}{|l|}{ Updated ADO index } \\
\hline $\mathrm{FEV}_{1}$ (\% predicted) & $\geq 81$ & $65-80$ & $51-64$ & $36-50$ & $\leq 35$ & & \\
\hline Dyspnoea (mMRC, 0-4) & $\overline{0}$ & $1-2$ & 3 & 4 & & & \\
\hline Age (in years) & $40-49$ & & $50-59$ & & $60-69$ & $70-79$ & $\geq 80$ \\
\hline \multicolumn{8}{|l|}{ Original ADO index } \\
\hline $\mathrm{FEV}_{1}$ (\% predicted) & $\geq 65$ & $36-64$ & $\leq 35$ & & & & \\
\hline Dyspnoea (mMRC, 0-4) & $0-1$ & 2 & 3 & 4 & & & \\
\hline Age (years) & $40-49$ & $50-59$ & $60-69$ & $70-79$ & $80-89$ & $\geq 90$ & \\
\hline
\end{tabular}

the ADO index classifies patients more correctly above or below certain risk thresholds than only $\mathrm{FEV}_{1}$, and this gain is especially relevant in subjects with very low and low risk of 3-year mortality where the benefit harm balance may be unfavourable. ${ }^{3} 4$ Although most COPD treatments are not prescribed to modify mortality risk, but to reduce exacerbations, and improve symptoms and quality of life, similar estimates for the benefit harm balance could be made for patients at low risk for exacerbations. Therefore, in the future, the ADO index should be complemented by other widely validated risk tools that make accurate projections about the risk for important outcomes in COPD, including exacerbations or worsening quality of life, in order to balance the benefits and harms of possible treatments.

In addition, accurate prediction of mortality by the ADO index can be used in clinical trials to base sample size calculations on realistic estimates of expected event rates, to target treatments to specific risk groups, for prestratification or to adjust for potential baseline imbalances. Also, the ADO index could be useful for the evaluation of biomarkers. Currently, major studies are being carried out to identify biomarkers that might help

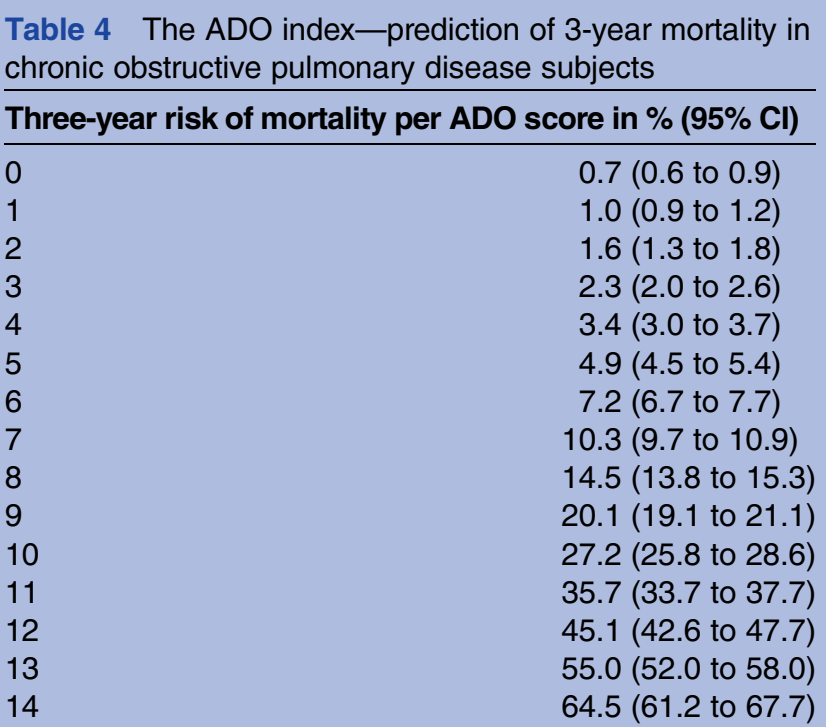

OR per 1 point increase in ADO index: 1.48 (95\% Cl 1.45 to 1.52). Area under the curve: $0.81(95 \% \mathrm{Cl} 0.80$ to 0.82$)$. to improve outcome prediction and response to treatments. The use of such biomarkers in clinical practice seems justified if they add significantly to the prediction based on easily available information. The ADO index is a simple tool that could serve as reference against which the additional value of biomarkers to predict mortality could be assessed. Therefore, the ADO index is likely to be useful for both medical practice and research.

A limitation to the current study is the use of mortality as the only assessed outcome, since COPD morbidity includes other relevant outcomes such as exacerbations, hospital admissions, or quality-of-life. Thus, our study should be considered a simplification of the clinical setting but it may pave the way for similar research evaluating risk prediction of additional outcomes. Once risk tools for various important outcomes and improved evidence about benefit and harm of treatments to modify these risks are available, informed decisions for providing the most appropriate care can be better supported. Our study was confined to a limited number of readily available predictors; therefore, variables with potential relevance to mortality risk such as exacerbation frequency or measures of exercise capacity were not included. This may also be perceived as strength of our study because it uses information readily available in routine clinical practices, including primary care settings, where most COPD patients are treated. Additional strengths of our study include the already mentioned large sample size and diversity of the populations. This increases external validity, which in this context means that recalibrations in populations different from those included in our analyses do not seem necessary. Lastly, by using decision curve analysis we looked beyond standard metrics for the performance of risk tools (discrimination and calibration) by providing an interpretation of the risk model that refers to different risk thresholds that may be used to inform treatment decisions.

In conclusion, the updated 15-point ADO index is a simple tool that can be used in diverse settings to inform patients and their caregivers about prognosis. Using risk tools in clinical COPD research may also help to design clinical trials and to inform policy makers, regulatory agencies or guideline developers when estimating the benefit harm balance and to serve as a reference standard for risk prediction against which the 
Figure 2 Accuracy of four strategies to classify subjects into risk categories. The upper part (A) of the figure shows the net benefit of six strategies to classify subjects with chronic obstructive pulmonary disease. The higher the values for net benefit the more patients are correctly classified. Two strategies do not use any predictors but assume that all patients would be above or below a risk threshold. The four other strategies use the ADO index, age, dyspnoea or $\mathrm{FEV}_{1}$ and associated risks of 3-year mortality to classify patients. Net benefit is defined as the difference between the proportion of correctly classified subjects and the proportion of subjects classified incorrectly to be at or above a risk threshold (eg, $5 \%$ risk). The line for considering all patients to be above a risk threshold crosses that line for considering all patients to be below a risk threshold at the death rate observed (9.7\%). The lower part of the graph (B) shows that, for example at a threshold of $5 \%$ mortality risk, using the ADO index would result in a net benefit similar to the reduction of 33 incorrectly classified patients per 100 subjects compared to considering all patients to be above a $5 \%$ mortality risk. Using age, dyspnoea or FEV 1 only would reduce it by only 24,10 and 18 per 100 subjects, respectively. The graph is restricted to subjects at low to moderate risk for 3-year mortality $(<20 \%)$ where most uncertainty about the balance between benefits and harms from treatment may exist. a)

Net Benefit

(Difference between correctly and incorrectly classified patients)

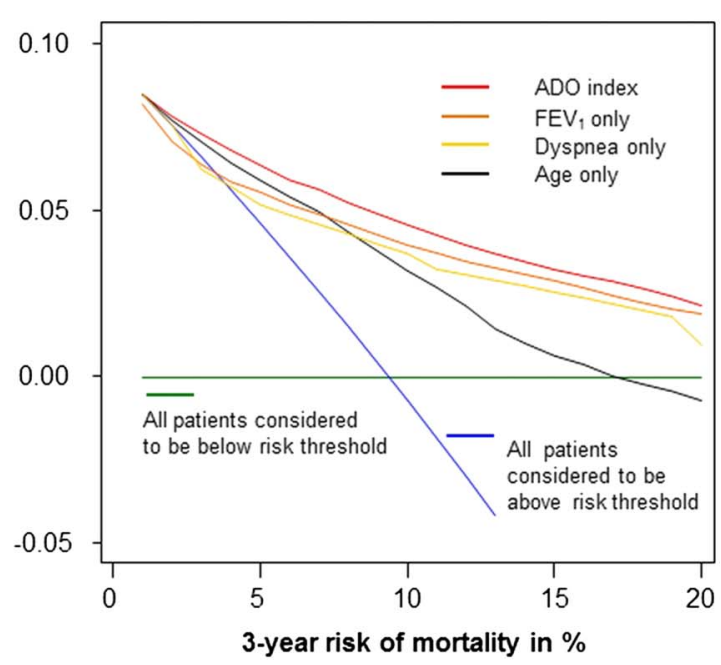

b)

$\%$ of patients that can be
avoided to be classified
incorrectly above risk
threshold compared to a
strategy where all patients are
considered to be above risk
threshold

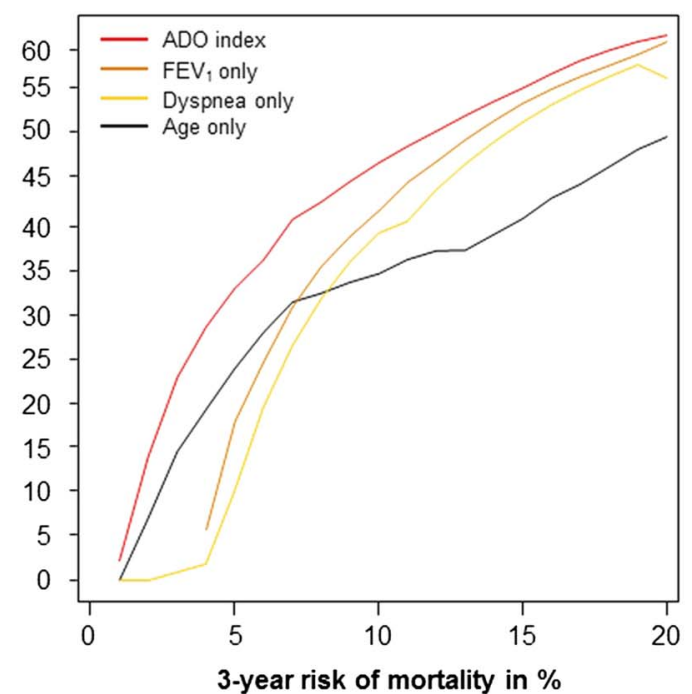

additional value of various biomarkers to predict mortality could be assessed.

\footnotetext{
Author affiliations

${ }^{1}$ Department of Epidemiology, Johns Hopkins Bloomberg School of Public Health, Baltimore, Maryland, USA

${ }^{2}$ Horten Centre, University of Zurich, Zurich, Switzerland

${ }^{3}$ Division of Pulmonary \& Critical Care Medicine, Johns Hopkins School of Medicine, Baltimore, Maryland, USA

${ }^{4}$ CIBER Enfermedades Respiratorias (CIBERES), Fundación Caubet-Cimera, Mallorca, Spain

${ }^{5}$ College of Public Health, The University of Arizona, Tucson, Arizona, USA

${ }^{6}$ Pulmonary Division, Hvidovre Hospital, Hvidovre, Danmark
}

${ }^{7}$ Jackson Heart Study, Coordinating Center, Jackson State University, Jackson, Mississippi, USA

${ }^{8}$ Department of Medicine, University of Mississippi Medical Center, Jackson, Mississippi, USA

${ }^{9}$ Federal University of Pelotas, Pelotas, Brazil

${ }^{10}$ Department of General Practice, Academic Medical Centre, University of Amsterdam, Amsterdam, The Netherlands

${ }^{11}$ Hospital del Mar Research Institute (IMIM), Barcelona, Spain

${ }^{12}$ Cedars Sinai Medical Center, David Geffen School of Medicine at UCLA, Los Angeles, California, USA

${ }^{13}$ Center for Research in Environmental Epidemiology (CREAL), Barcelona Spain

${ }^{14}$ Universitat Pompeu Fabra, Barcelona, Spain

${ }^{15}$ CIBER de Epidemiologia y Salud Pública (CIBERESP), Barcelona, Spain 
${ }^{16}$ Department of Epidemiology, Julius Centre for Health Sciences and General Practice, University Medical Center, Utrecht, The Netherlands

${ }^{17}$ Clinical Epidemiology, and Medical Technology Assessment, University Hospital Maastricht, Maastricht, The Netherlands

Collaborators Cohorts and investigators of the International COPD Cohorts Collaboration Working Group: Barmelweid cohort (Switzerland)-Martin Frey, MD, Klinik Barmelweid, Switzerland; Ulrike Held, PhD, Horten Centre, University of Zurich, Switzerland; Milo A. Puhan, MD, PhD, Johns Hopkins Bloomberg School of Public Health, Baltimore, USA and Horten Centre, University of Zurich, Switzerland. Basque study (Spain)—Milagros Iriberri Pascual, MD, Cruces Hospital, Baracaldo, Basque Country, Spain; Patricia Sobradillo, MD, CIBER Enfermedades Respiratorias (CIBERES), Fundación Caubet-Cimera, Mallorca, Spain. Cardiovascular Health Study (USA)-R. Graham Barr, MD, Department of Medicine, College of Physicians and Surgeons, Columbia University, New York, USA; Paul Enright, MD, College of Public Health, The University of Arizona, Tucson, Arizona, USA; Jerry Krishnan, MD, Department of Medicine, Section of Pulmonary and Critical Care, University of Chicago, Chicago, USA; Tony Wilson, Department of Biostatistics, University of Washington, Seattle, USA; Sachin Yende, MD, Department of Critical Care Medicine, University of Pittsburgh, Pittsburgh, Pennsylvania, USA. Copenhagen City Heart City study (Denmark)-Peter Lange, MD, Pulmonary Division, Hvidovre Hospital, Hvidovre, Danmark. Jackson Heart Study (USA)—DeMarc Hickson, PhD, MPH, Jackson State University, Jackson Heart Study, Coordinating Center, USA. Department of Medicine, University of Mississippi Medical Center, USA; Wendy White, PhD, MPH, Tougaloo College, Jackson Heart Study, USA. Lung Health Study (USA)—Nadia Hansel, MD, MPH, and Robert A. Wise, MD, Division of Pulmonary \& Critical Care Medicine, Johns Hopkins School of Medicine, Baltimore, USA. National Emphysema Treatment Trial (USA)-Fernando Martinez, MD, Division of Pulmonary and Critical Care Medicine, University of Michigan Health System, Ann Arbor, USA; Zab Mosenifar, MD, Cedars Sinai Medical Center, David Geffen School of Medicine at UCLA, Los Angeles, USA; Andrew Ries, MD, Department of Medicine, University of California, San Diego, USA; James K. Stoller, MD, MS, Respiratory Institute, Department of Pulmonary and Critical Care Medicine, Cleveland Clinic Foundation, Cleveland, USA; Robert A. Wise, MD, see above. PAC-COPD (Spain)—Alvar Agustí, MD, Federico P Gómez, MD, and Roberto Rodriguez-Roisin, MD, Department of Pneumology, Thorax Institute, Hospital Clinic, Institut d'Investigacions Biomèdiques August Pi i Sunyer, Barcelona, and CIBER Enfermedades Respiratorias (CIBERES), Spain; Josep M Antó, MD, PhD, and Judith Garcia-Aymerich, MD, PhD, (1) Center for Research in Environmental Epidemiology (CREAL), Barcelona, Spain, (2) Hospital del Mar Research Institute (IMIM), Barcelona, Spain, (3) Universitat Pompeu Fabra, Barcelona, Spain, (4) CIBER de Epidemiologia y Salud Pública (CIBERESP), Spain. PLATINO study team (Brazil, Uruguay)—Ana MB Menezes, MD, PhD, Federal University of Pelotas, Pelotas, Brazil; Maria Victorina Lopez, MD, and Adriana Muiño, MD, Universidad de la República, Montevideo. Uruguay. SEPOC study (Spain)-Josep M Antó, MD, PhD, see above; Antonia Domingo-Salvany, MD, PhD, Hospital del Mar Research Institute (IMIM), Barcelona, Spain; Judith Garcia-Aymerich, MD, PhD, see above; Methodological and Statistical team; Judith Garcia-Aymerich, MD, PhD, see above; Nadia Hansel, MD, MPH, see above; Ulrike Held, PhD, see above; Alphons Kessels, MD, Clinical Epidemiology, and Medical Technology Assessment, University Hospital Maastricht, Maastricht, The Netherlands; Karel GM Moons, PhD, Julius Centre for Health Sciences and General Practice, University Medical Center, Utrecht, The Netherlands; Milo A. Puhan, MD, PhD, see above; Gerben ter Riet, Department of General Practice, Academic Medical Centre, University of Amsterdam, The Netherlands; Ignasi Serra, Center for Research in Environmental Epidemiology, Barcelona, Spain.

Contributors MP, NH and JGA conceived the study idea, contributed to the statistical analysis and drafted the first version of the manuscript. MF, UH and MP oversaw all activities related to the conduct of the Barmelweid cohort (Switzerland). MIP and PS oversaw all activities related to the conduct of the Basque study (Spain). RGB, PE, JK and TW oversaw all activities related to the conduct of the Cardiovascular Health Study (USA). PL oversaw all activities related to the conduct of the Copenhagen City Heart City study (Denmark). DMH and WW oversaw all activities related to the conduct of the Jackson Heart Study (USA). NH and RW oversaw all activities related to the conduct of the Lung Health Study (USA). FM, ZM, AR and RW oversaw all activities related to the conduct of the National Emphysema Treatment Trial (USA). AA, FPG, RRR, JMA and JGA oversaw all activities related to the conduct of the PAC-COPD (Spain). AMM, MVL and AM oversaw all activities related to the conduct of the PLATINO study team (Brazil, Uruguay). JMA, ADS and JGA oversaw all activities related to the conduct of the SEPOC study (Spain). UH, AK, KGM, GtR and IS contributed to the statistical analysis. All authors revised the manuscript and accepted the final version.

Funding The Barmelweid cohort (Switzerland) was funded by the Swiss National Science Foundation (grant number 3233B0-115216) and by the Klinik Barmelweid. Basque study (Spain): No external funding. The Cardiovascular Health Study is supported by NHLBI Grant/Contract numbers N01-HC-85239, N01-HC-85079 through N01-HC-85086; N01-HC-35129, N01 HC-15103, N01 HC-55222, N01-HC-75150, N01-HC-45133; HL080295, HL-075366; NIA Grant/Contract numbers AG-023269, AG-15928, AG-20098, and AG-027058; University of Pittsburgh Claude. D. Pepper Older Americans Independence Center grant number P30-AG-024827; with additional contribution from NINDS. See also http://www.chs-nhlbi.org/pi.htm The Copenhagen City Heart City study (Denmark) was supported by grants from The Danish Heart Foundation, The Danish Lung Association and Danish Medical Research Council. The Jackson Heart Study (JHS) is a collaborative study supported by the National Institutes of Health and the National Center on Minority Health and Health Disparities (study ID numbers: 5001; N01 HC95170; N01 HC95171; N01 HC95172) in partnership with Jackson State University, Tougaloo College, and University of Mississippi Medical Center. The Lung Health Study (USA) was supported by contract NIH/N01-HR-46002 from the National Heart, Lung and Blood Institute (NHLBI). The National Emphysema Treatment Trial (USA) is funded by the National Heart, Lung and Blood Institute, the Centers for Medicare and Medicaid Services, and the Agency for Healthcare Research and Quality. The PAC-COPD Study is funded by grants from Fondo de Investigación Sanitaria (FIS PI020541), Ministry of Health, Spain; Agència d'Avaluació de Tecnologia i Recerca Mèdiques (AATRM 035/20/02), Catalonia Government; Spanish Society of Pneumology and Thoracic Surgery (SEPAR 2002/137); Catalan Foundation of Pneumology (FUCAP 2003 Beca Marià Ravà); Red RESPIRA (RTIC C03/11); Red RCESP (RTIC C03/09), Fondo de Investigación Sanitaria (PI052486); Fondo de Investigación Sanitaria (PI052302); Fundació La Marató de TV3 (num. 041110); DURSI (2005SGR00392); and an unrestricted educational grant from Novartis Farmacèutica, Spain. CIBERESP and CIBERES are funded by the Instituto de Salud Carlos III, Ministry of Health, Spain. PLATINO study was funded by ALAT (Associacion Latino Americana del Tórax); Boehringer Ingelheim GmbH (BI), and GlaxoSmithKline (GSK). The SEPOC study (Spain) was supported by grants from Fondo de Investigación Sanitaria 99/0690 and CIRIT 1999SGR00240. Judith Garcia-Aymerich has a researcher contract from the Instituto de Salud Carlos III (CP05/00118), Ministry of Health, Spain. Karel G.M. Moons receives funding from the Netherlands Organisation for Scientific Research (project 9120.8004 and 918.10.615).

Competing interests None.

Ethics approval Ethics Committees of each participating hospital/reserach institute.

Provenance and peer review Not commissioned; externally peer reviewed.

Data sharing statement No additional data are available.

\section{REFERENCES}

1. Lopez AD, Shibuya K, Rao C, et al. Chronic obstructive pulmonary disease: current burden and future projections. Eur Respir $J$ 2006;27:397-412.

2. Mathers CD, Loncar D. Projections of global mortality and burden of disease from 2002 to 2030. PLoS Med 2006;3:e442.

3. Guo JJ, Pandey S, Doyle J, et al. A review of quantitative risk-benefit methodologies for assessing drug safety and efficacy-report of the ISPOR risk-benefit management working group. Value Health 2010;13:657-66.

4. Kent DM, Hayward RA. Limitations of applying summary results of clinical trials to individual patients: the need for risk stratification. JAMA 2007;298:1209-12. 
5. Politi MC, Han PK, Col NF. Communicating the uncertainty of harms and benefits of medical interventions. Med Decis Making 2007;27:681-95.

6. Moons KG, Royston P, Vergouwe $\mathrm{Y}$, et al. Prognosis and prognostic research: what, why, and how? BMJ 2009;338:b375.

7. Global Strategy for Diagnosis, Management, and Prevention of COPD. 2010. http://wwwgoldcopdcom/GuidelinesResourcesasp? $|1=2 \&| 2=0$ (accessed 10 Sept 2012).

8. Celli BR, MacNee W. Standards for the diagnosis and treatment of patients with COPD: a summary of the ATS/ERS position paper. Eur Respir J 2004;23:932-46.

9. National Cholesterol Education Program (NCEP) Expert Panel on Detection, Evaluation, and Treatment of High Blood Cholesterol in Adults (Adult Treatment Panel III). Third Report of the National Cholesterol Education Program (NCEP) Expert Panel on Detection, Evaluation, and Treatment of High Blood Cholesterol in Adults (Adult Treatment Panel III) final report. Circulation 2002;106:3143-421.

10. American Diabetes Association. Standards of medical care in diabetes. Diabetes Care 2011;34(Suppl 1):S11-61.

11. National Collaborating Centre for Cancer. NICE clinical guideline 58: Prostate cancer: diagnosis and treatment. National Institute for Health and Clinical Excellence. 2008. http://www.nice.org.uk/cg58 (accessed 10 Sept 2012).

12. National Collaborating Centre for Cancer. NICE clinical guideline 80 : Early and locally advanced breast cancer: diagnosis and treatment. National Institute for Health and Clinical Excellence. 2009. http:// www.nice.org.uk/cg80 (accessed 10 Sept 2012).

13. US Preventive Services Task Force. Aspirin for the prevention of cardiovascular disease: U.S. Preventive Services Task Force recommendation statement. Ann Intern Med 2009;150:396-404

14. Puhan MA, Zoller M, ter Riet G. COPD: more than respiratory. Lancet 2008;371:27-8.

15. Jones RC, Donaldson GC, Chavannes $\mathrm{NH}$, et al. Derivation and validation of a composite index of severity in chronic obstructive pulmonary disease: the DOSE Index. Am J Respir Crit Care Med 2009;180:1189-95.

16. Celli BR, Cote CG, Marin JM, et al. The body-mass index, airflow obstruction, dyspnea, and exercise capacity index in chronic obstructive pulmonary disease. N Engl J Med 2004;350:1005-12.

17. Puhan MA, Garcia-Aymerich J, Frey M, et al. Expansion of the prognostic assessment of patients with chronic obstructive pulmonary disease: the updated BODE index and the ADO index. Lancet 2009;374:704-11.

18. Altman DG, Royston P. What do we mean by validating a prognostic model? Stat Med 2000;19:453-73.

19. Altman DG, Vergouwe $Y$, Royston $P$, et al. Prognosis and prognostic research: validating a prognostic model. BMJ 2009;338:b605.

20. Steyerberg EW, Bleeker SE, Moll HA, et al. Internal and external validation of predictive models: a simulation study of bias and precision in small samples. J Clin Epidemiol 2003;56:441-7.

21. Janssen KJ, Moons KG, Kalkman CJ, et al. Updating methods improved the performance of a clinical prediction model in new patients. J Clin Epidemiol 2008;61:76-86.
22. Sobradillo $\mathrm{P}$, Iriberri $\mathrm{M}$, Gomez $\mathrm{B}$, et al. Validation of bode index as a predictor of mortality in COPD patients. 18th Annual Congress of the European Respiratory Society. Berlin: European Respiratory Society, 2008:P531.

23. Fried LP, Borhani NO, Enright $\mathrm{P}$, et al. The Cardiovascular Health Study: design and rationale. Ann Epidemiol 1991;1:263-76.

24. Appleyard M, Hansen A, Schnohr P. The Copenhagen City Heart Study: a book of tables with data from the first examination (1976-78) and a five years follow-up (1981-1983). Scand J Soc Med 1989;170:1-160.

25. Carpenter MA, Crow R, Steffes M, et al. Laboratory, reading center, and coordinating center data management methods in the Jackson Heart Study. Am J Med Sci 2004;328:131-44.

26. Connett JE, Kusek JW, Bailey WC, et al. Design of the Lung Health Study: a randomized clinical trial of early intervention for chronic obstructive pulmonary disease. Control Clin Trials 1993;14:3S-19S.

27. Fishman A, Martinez F, Naunheim K, et al. A randomized trial comparing lung-volume-reduction surgery with medical therapy for severe emphysema. N Engl J Med 2003;348:2059-73.

28. Garcia-Aymerich J, Gomez FP, Anto JM. Phenotypic Characterization and Course of Chronic Obstructive Pulmonary Disease in the PAC-COPD Study: design and methods. Arch Bronconeumol 2009;45:4-11.

29. Menezes AM, Perez-Padilla R, Jardim JR, et al. Chronic obstructive pulmonary disease in five Latin American cities (the PLATINO study): a prevalence study. Lancet 2005;366:1875-81.

30. Domingo-Salvany A, Lamarca R, Ferrer M, et al. Health-related quality of life and mortality in male patients with chronic obstructive pulmonary disease. Am J Respir Crit Care Med 2002;166:680-5.

31. Moons KG, Donders RA, Stijnen T, et al. Using the outcome for imputation of missing predictor values was preferred. J Clin Epidemiol 2006;59:1092-101.

32. Steyerberg E. Applications of prediction models. In: Steyerberg E (ed.). Clinical prediction models-a practical approach to development, validation, and updating. New York: Springer, 2010. pp. 281-310

33. Sullivan LM, Massaro JM, D'Agostino RB. Presentation of multivariate data for clinical use: the Framingham Study risk score functions. Stat Med 2004;23:1631-60.

34. Vickers AJ. Decision analysis for the evaluation of diagnostic tests, prediction models and molecular markers. Am Stat 2008;62:314-20.

35. Vickers AJ, Elkin EB. Decision curve analysis: a novel method for evaluating prediction models. Med Decis Making 2006;26:565-74.

36. Cazzola M, MacNee W, Martinez FJ, et al. Outcomes for COPD pharmacological trials: from lung function to biomarkers. Eur Respir J 2008;31:416-69.

37. Gail MH. The estimation and use of absolute risk for weighing the risks and benefits of selective estrogen receptor modulators for preventing breast cancer. Ann N Y Acad Sci 2001;949:286-91. 